\title{
Fighting science with politics
}

\author{
Emergency contraceptive pills have long been a hot button issue in US politics due to their mischaracterization as \\ inducing abortion and promoting promiscuity, leading to delayed approvals and restricted access. A recent decision \\ on the Plan B One-Step pill suggests that, once again, science has taken a back seat to politics.
}

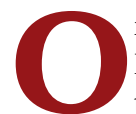
n 7 December, Secretary Kathleen Sebelius of the US Department of Health and Human Services (HHS) blocked the decision by the US Food and Drug Administration (FDA) to approve over-the-counter (OTC) sales of the emergency contraceptive Plan B One-Step to women aged 16 and younger (see page 8 ). Sebelius's action marks the first instance in which the HHS has overruled a verdict by the FDA, and it sets a disturbing precedent for the ability of the FDA to act independently of outside interests in assessing the safety and efficacy of drugs and medical devices.

Plan B One-Step, marketed by Teva Pharmaceuticals, is a single-dose, levonorgestrel-based contraceptive for use in women within 72 hours of unprotected sex to prevent ovulation or fertilization. Products containing levonorgestrel, a synthetic progestogen, have been sold in the US since 1982 and are considered safe and well tolerated. Single-dose, levonorgestrel-only emergency contraceptives have been available without a prescription in many countries for several years, contributing to the overall safety profile of the product. Yet this collective global experience seems to have been often ignored in regulatory decisions on emergency contraceptives in the US.

In 1999, a two-dose predecessor to One-Step (called simply Plan B) was approved in the US as a prescription-only emergency contraceptive. In 2003, Women's Capital Corporation (acquired by Barr Pharmaceuticals, now owned by Teva) requested a switch for Plan B to OTC status. The FDA Advisory Committee on Reproductive Health Drugs and Nonprescription Drugs recommended the change, concluding that use of Plan B was safe for all women of reproductive age.

But in 2004 the request was denied by the acting director of the FDA's Center for Drug Evaluation and Research, who was not persuaded that the data were sufficient to conclude that the product could be used safely by young women without medical oversight. The application included a study of Plan B use in 585 individuals, but only 29 were between the ages of 14 and 16, and none were younger than 14. The FDA informed the company that approval of their application would require either data showing safe use in the absence of medical supervision in the younger population or a plan and appropriate labeling for marketing the drug as both prescription based for women younger than 16 and nonprescription for women 16 and older.

Pursuant to that decision, Barr Pharmaceuticals formally requested that Plan B be switched to nonprescription status for women 16 and older but was again rebuffed. The FDA commissioner, Lester Crawford, alerted the company more than a year later that although a switch to OTC status for women aged 17 and older was supported by the data, there continued to be concerns about marketing Plan B as both a prescription and nonprescription product that precluded its approval. The decision prompted one senior FDA official to resign in protest of decision making that ignored the evidence-based recommendations of the FDA staff. Underscoring this view was the decision by the subsequent FDA commissioner, Andrew von Eschenbach, that, owing to potential difficulties in enforcing an age restriction for Plan B, "18 (rather than 17) is the more appropriate cutoff point to best promote and protect the public health." In 2006, Plan B was finally approved as a nonprescription drug only for women aged 18 and older. No scientific rationale was ever offered by the FDA commissioners for the restriction of its OTC access to 16- and 17-year-olds.

The unusual delays and the rejection of the recommendation from the FDA advisory committee prompted an investigation by the Government Accountability Office (GAO). Among a number of irregularities noted by the GAO, of 67 drug applications for a switch to OTC status between 1994 and 2004, the Plan B request was the only one to be denied despite a positive recommendation by the FDA advisory committee. The FDA leadership's decision making on Plan B was similarly found to be "arbitrary and capricious" by a federal judge who ordered the FDA in 2009 to make the product available to women 17 and older without a prescription.

In early 2011, Teva requested the switch to OTC status for Plan B One-Step, which is also nonprescription only for women 17 and older, submitting new data on its use by younger women. This time, FDA commissioner Margaret Hamburg was prepared to approve the request but was stopped by Sebelius' action. As was invoked in the 2004 decision on Plan B, Sebelius claimed that there was insufficient evidence to conclude that younger women could fully understand and properly use the drug. She did not question its safety. The FDA scientists' recommendation clearly disputes Sebelius' conclusion, and the GAO, in 2005, indicated that age-related distinctions in cognitive ability had never previously had a role in decisions to switch a drug to OTC status.

Sebelius is not a scientist and says her decision was uninfluenced by politics. But she is a politician and therefore attuned to the political implications of her decision, particularly with a US presidential election looming. As the FDA scientists have more than a decade of regulatory experience with Plan B, to dismiss their insight and scientific evaluation seems short sighted at best and health threatening at worst.

Sebelius acted under her authority to oversee the FDA's decisions, but, given that the move is unprecedented, its explanation requires greater transparency. It has been suggested to make the FDA exempt from HHS oversight, which would relieve it of some political and ideological pressures. Alternatively, the HHS should enter into discussions with the FDA prior to unilaterally overruling a decision and undermining the FDA's credibility and role. Drug approvals need to be based on a rigorous evaluation of clinical and scientific evidence and not on political merit. Public health will not be well served if the FDA must consider the political ramifications of its decisions. 